\title{
STRUCTURE AND BEHAVIOUR OF GRAIN BOUNDARIES IN POLYGRYSTALLINE ICE
}

\author{
By Akira Higashi \\ (Department of Applied Physics, Faculty of Engineering, Hokkaido University, Sapporo, \\ Japan o6o)
}

\begin{abstract}
Recent progress in studies of the structure and behaviour of grain boundaries in ice are reviewed. As a lattice geometrical model of the boundary, the coincidence-site lattice (CSL) model is considered for ice crystals. Some evidence of the validity of this model is presented through observations of special shapes of natural snow, results of grain-boundary energy measurements, and direct microscopic observations of boundaries by X-ray diffraction topography. Although methods of measurement of grainboundary energy have been developed recently, results are still not adequate to be analysed in terms of real energetics for comparison with models of atomic bonding. Modern methods of observing grain boundaries in ice using X-ray diffraction topography are described. Observations of migrating boundaries have revealed that faceting along most closely packed CSL points impede the migration of the CSL boundaries whilst increased numbers of steps among facets with boundaries of other kinds enhance it. The mobility of a fastmoving boundary has been determined to be of the order of $10^{-10} \mathrm{~cm}^{3} \mathrm{dyn}^{-1} \mathrm{~s}^{-1}\left(10^{-11} \mathrm{~m}^{3} \mathrm{~N}^{-1} \mathrm{~s}^{-1}\right)$ either in the case when the driving force is the capillary force due to the boundary energy or when it is the stored energy of dislocations.
\end{abstract}

RÉsumé. Structure et comportement des joints de grains dans la glace polycristalline. Nous passons en revue les progrès récents concernant la structure et le comportement des joints de grains dans la glace. Nous avons considéré le modèle géométrique des réseaux en coïncidence et l'avons appliqué au cas de la glace. La validité d'un tel modèle est appuyée par l'observation de certaines formes particulières de la neige naturelle, les résultats relatifs aux mesures d'énergie de joint de grains et les observations directes de joints par topographie aux rayons X. Malgré les développements récents des méthodes de mesure de l'énergie de joint de grains, les résultats ne sont pas encore suffisants pour être analysés en terme de théorie atomique. Nous décrivons une nouvelle méthode d'observation des joints de grains dans la glace à l'aide de la diffraction des rayons $\mathrm{X}$. L'observation de la migration des joints révèle que l'accolement de grains sur un plan à haute densité de site en coïncidence conduit à un joint moins mobile alors que les autres joints, présentant des marches, sont plus mobiles. La mobilité des joints les plus rapides a été déterminée et est de l'ordre de ${ }^{1} 0^{-10} \mathrm{~cm}^{3} \mathrm{dyn}^{-1} \mathrm{~s}^{-1}$ $\left(\mathrm{IO}^{-1 \mathrm{II}} \mathrm{m}^{3} \mathrm{~N}^{-1} \mathrm{~s}^{-1}\right)$ soit dans le cas où la force motrice est associée à l'énergie de joint soit dans celui où cette force motrice est associée à l'énergie de défauts (dislocations).

Zusammenfassung. Struktur und Verhalten von Korngrenzen in polykristallinem Eis. Es wird ein Überblick über die jüngsten Fortschritte bei den Untersuchungen der Struktur und des Verhaltens von Korngrenzen in Eis gegeben. Als ein gittergeometrisches Modell der Korngrenze wurde das Koinzidenzstellengitter(CSL-) modell bei Eiskristallen betrachtet. Einige Beweise für die Gültigkeit dieses Modells wurden durch die Beobachtungen besonderer Formen natürlichen Schnees, durch die Messung der Korngrenzenenergie und unmittelbare mikroskopische Beobachtungen der Korngrenzen durch Röntgenbeugungstopographie vorgelegt. Obwohl Verfahren für die Messung der Korngrenzenenergie vor kurzem entwickelt wurden, sind die Ergebnisse immer noch nicht ausreichend, um vom Standpunkt wirklicher Energieverhältnisse mit bestimmten Modellen der atomaren Bindungen untersucht werden zu können. Ein neues Beobachtungsverfahren für Korngrenzen in Eis mit Röntgenbeugungstopographie wird beschrieben. Beobachtungen wandernder Korngrenzen zeigten, dass Facettenbildung entlang dichtest gepackter CSL-Punkte die Wanderung der CSL-Grenzflächen hindert, während erhöhte Stufenzahl zwischen Facetten mit Grenzflächen anderer Art sie vergrössert. Die Beweglichkeit der sich schnell bewegenden Korngrenze wurde in der Grössenordnung von $10^{-10} \mathrm{~cm}^{3} \mathrm{dyn}^{-1} \mathrm{~s}^{-1}\left(1 \mathrm{O}^{-11} \mathrm{~m}^{3} \mathrm{~N}^{-1} \mathrm{~s}^{-1}\right)$ bestimmt, entweder im Fall einer Kapillarkraft infolge der Grenzenergie als treibender Kraft oder im Fall gespeicherter Versetzungsenergie als Quelle der treibenden Kraft.

\section{Introduction}

The mechanical properties of polycrystalline ice are of practical importance, because it is the real existing state of bulk ice in the hydrosphere on the earth. Recently our emphasis in the study of mechanical properties of ice has moved from the processes which occur inside its constituent single crystals to those which are governed by the boundaries between the grains. Various phenomena such as creep, yielding, and fracture of ice, grain growth and metamorphosis in polycrystalline ice, etc., all depend upon effects of grain boundaries in addition to elementary processes in individual grains. Compared with situations in the study area of metals, the study of grain boundaries in ice is still immature. However, some important 
contributions to the study which have appeared recently are enough to stimulate writing this review. For readers who wish to have general acquaintance with recent developments in the area of grain-boundary problems, several books are recommended (Bruggeman and others, 1972; Chadwick and Smith, I972; Chaudari and Matthews, I972).

First, it should be noted that this paper is limited to a review of the grain boundaries in pure ice. If impurities are involved, phenomena like impurity segregation to the boundary, impurity diffusion in the boundary, and other effects may occur, and they make the processes associated with grain boundaries complex. Although those phenomena are interesting in themselves, we avoided those subjects in this paper.

With respect to the structure of grain boundaries, there are two methods of approach; lattice geometrical models and energetic considerations. In the geometrical approach, the coincidence-site lattice (CSL) model of the grain boundary has been developed extensively in the last decade to interpret the structure of high-angle grain boundaries which exhibit special properties at definite angles of misorientation. Although Bollmann's o-lattice model (Bollmann, 1970) is the most developed model which has generalized the coincidence model for all systems, the CSL model has been most commonly used. In this paper, developments and generalization of the CSL concept to the case of ice will be given in detail, with applications to the understanding of the peculiar shapes of snow crystals, etc.

The alternative method is to consider the grain-boundary energy both for examining the validity of the models as proposed by the CSL concept and for interpreting the behaviour of grain boundaries. Recent developments in measuring the grain-boundary energy of ice are described and results of measurements are interpreted in the light of the CSL concept.

With respect to the behaviour of grain boundaries in ice, microscopic observations using $\mathrm{X}$-ray diffraction topography revealed differences in the appearance of defect images between the well-fitted boundaries according to the CSL concept and other arbitrary boundaries in specimens subjected to stress. A model of the structure of a near-CSL boundary in ice is presented. Results of macroscopic observations of the movement of grain boundaries of recrystallized portions in sharply bent ice crystals were analysed using strain-energy considerations based on the dislocation model of small-angle boundaries. The mobility of grain boundaries were measured from these observations as well as from other experiments of the boundary migration due to its local capillary force.

\section{Strugtures of Grain boundaries in IGE}

\section{II-I. Dislocation models of small-angle boundaries in ice}

The first step in applying the dislocation model of small-angle boundaries to ice was taken when the present author and his colleague (Higashi and Sakai, I96r) measured the movement velocity of small-angle boundaries driven by stress in ice single crystals. Although the method of observing the movement was different, the idea of these experiments was the same as that carried out with zinc by Washburn and Parker (1952). The experiments revealed that smallangle boundaries perpendicular to the basal plane are formed of arrays of dislocations and the velocity of movement could be considered as that of individual dislocations aligned in a row with a considerable distance between. Interest in the stress dependence of dislocation velocity in ice thus determined was revived recently in conjunction with its direct measurements by X-ray diffraction topography (Weertman, I973; Fukuda and Higashi, I973).

There will be no need to describe the model here because it is so well known and can be found in any text-book of dislocation theory (for example Read, r953) and in some general text-books on solid-state physics or material science. Variation of the grain-boundary energy with misfit angle $\theta$ derived from this model may be worth citing:

$$
E=\frac{\mu b}{4 \pi(\mathrm{I}-\nu)} \theta(A-\log \theta),
$$


where $\mu, \nu$, and $b$ represent the rigidity modulus, Poisson's ratio of the crystal, and Burgers vector of dislocations concerned respectively. $A$ is a constant which is associated with the core energy of dislocations. This equation will be used in sections on the energetics and on grainboundary migration later.

\section{II-2. Coincidence-site lattice (CSL) model}

It has been well known with metals that boundary properties vary both with misorientation and boundary plane. In particular, there are some special misorientations which exhibit higher mobilities in the presence of impurities and lower energies than those with arbitrary misorientations. To interpret this behaviour of special grain boundaries, the coincidence-site lattice (CSL) model was proposed by Kronberg and Wilson (1949), and since then it has achieved much success with various materials. Some direct evidence for the validity of the model were obtained by electron-microscopic and field-ion-microscopic observations.

It was shown that for certain misorientations about rational axes there exist superlattices on which a fraction $(\mathbf{I} / \Sigma)$ of the lattice points in the two crystals lie. The superlattice thus formed in interpenetrated lattice points of the two crystal grains is called a Coincidence-Site Lattice (CSL). Any CSL is characterized by a number $\Sigma$, a rotation axis [ $h k l]$, and a rotation angle $\theta$, between which the following relations hold for a three-dimensional CSL composed of cubic crystals:

$$
\theta=2 \tan ^{-1}(y / x) \sqrt{ } \mathcal{N},
$$

where $x$ and $y$ are integers and $\mathcal{N}=\left(h^{2}+k^{2}+l^{2}\right)$, and

$$
\Sigma=x^{2}+\mathcal{N} y^{2} \text {. }
$$

The number $\Sigma$, which is called the "reciprocal density of CSL points", means that in the unit cell of the CSL there exist $\Sigma$ lattice points of the two interpenetrating crystal lattices. The smaller this number is, the more common lattice points exist, and crystallographic planes of the CSL have a high density of coincident lattice points of both crystals. In the CSL theory of grain boundaries, such planes of good atomic fit are considered to correspond to special grain boundaries at which the boundary energy will be low. Therefore, lattices with smaller values of $\Sigma$ should be considered among the infinite number of them.

The CSL of the hexagonal system of crystals was first considered by Bruggeman and others (r972) for hexagonal closed-packed (HCP) metals. They gave tables of $\Sigma$ and $\theta$ pairs with rotation axes [OoOI], $\langle\mathbf{I} \overline{\mathrm{I}} \mathrm{O}\rangle$ and $\langle\mathrm{I} \mathbf{I} \overline{2} \mathrm{O}\rangle$, for values of $\Sigma$ less than 37. Similar calculations were performed (unpublished work by T. Hondoh) with a simple hexagonal lattice of which the axial ratio was $\sqrt{ }(8 / 3)$. This is a first approximation to the ice crystal lattice which takes a more complex structure than HCP. If we consider only cases in which the rotation axis is parallel to the basal plane, the equations corresponding to Equations (2) and (3) are

$$
\begin{aligned}
\theta & =2 \tan ^{-1}\left(\frac{3}{8}\right)^{\frac{1}{2}} \frac{m}{n}, \\
\Sigma & =\left(8 n^{2}+3^{2}\right) \frac{\mathrm{I}}{\beta},
\end{aligned}
$$

where $m$ and $n$ are integers and $\beta$ is the G.C.F. between $8 n$ and $3 m$.

Results of calculations with $\langle\overline{\mathrm{I}} 2 \overline{\mathrm{I}} \mathrm{O}\rangle$ and $\langle\mathrm{IO} \overline{\mathrm{I}} \mathrm{O}\rangle$ rotation axes for $\Sigma$ less than 50 are tabulated in Table I. The unit cells of the CSL have three types of rectangular prisms according to the selection of odd and even numbers for $m$ and $n$. Size of the unit cell changes with different values of $\Sigma$ but the direction of each side of the cell as indicated in Figure $\mathrm{I}$ is the same as expressed in the figure caption. Correspondence between the pairs $(n, m)$ and $\Sigma$ are as given in Table I. In Figure $I$ the origin of coordinates is $O$ and the direction of the rotation axis is os. 
TABle I. Coincidence-site lattices Formed By rotations ABout $\langle\overline{\mathrm{I}} 2 \overline{\mathrm{I}} \mathrm{O}\rangle$ AND $\langle$ IO $\bar{I} O\rangle$ OF SIMPLE HEXAGONAL LATTICES, $\Sigma<50$

Rotation axis $\langle\overline{\mathrm{I}} 2 \overline{\mathrm{I}} \mathrm{O}\rangle$

\begin{tabular}{|c|c|c|c|}
\hline $\begin{array}{l}\text { Rotation } \\
\text { angle } \theta \\
\text { deg }\end{array}$ & $(n, m)$ & $\Sigma$ & $\begin{array}{l}\text { Indices of } \\
O T T S \text { plane }\end{array}$ \\
\hline 26.53 & $(9.2)$ & $3^{8}$ & $(9 \circ \overline{9} 4)$ \\
\hline 38.94 & (3.I) & 27 & $(30 \overline{3} 2)$ \\
\hline $50.4^{8}$ & $(1.2)$ & 22 & (10 \\
\hline 55.88 & $(2.1)$ & $4^{I}$ & $(\mathrm{I} O \overline{\mathrm{I}} \mathrm{I})$ \\
\hline 70.53 & $(3.2)$ & I8 & $(30 \overline{3} 4)$ \\
\hline 86.63 & $(\mathrm{I} . \mathrm{I})$ & 17 & $(1012)$ \\
\hline
\end{tabular}

Rotation axis 〈n

\begin{tabular}{|c|c|c|c|}
\hline $\begin{array}{c}\text { Rotation } \\
\text { angle } \theta \\
\text { deg }\end{array}$ & $(n, m)$ & $\Sigma$ & $\begin{array}{l}\text { Indices of } \\
\text { OPTS plane }\end{array}$ \\
\hline 23.07 & $(3.1)$ & 25 & $\left(\overline{3}^{6} 6 \overline{3}^{2}\right)$ \\
\hline 34.05 & $(2.1)$ & 35 & $(\overline{\mathrm{I}} 2 \overline{\mathrm{I}} \mathrm{I})$ \\
\hline $44 \cdot 4^{2}$ & $(3.2)$ & 14 & $(\overline{3} 6 \overline{3} 4)$ \\
\hline 57.11 & $(1 \cdot 3)$ & 35 & $(\overline{\mathrm{I}} 2 \overline{\mathrm{I}} 6)$ \\
\hline 62.96 & (I.I) & I I & $(\overline{\mathrm{I}} 2 \overline{\mathrm{i}} 2)$ \\
\hline 78.46 & $(1.2)$ & IO & $(\overline{\mathrm{I}} 2 \overline{\mathrm{I}} 4)$ \\
\hline 88.83 & $(3.5)$ & 49 & $(\overline{3} 6 \overline{3} 10)$ \\
\hline
\end{tabular}

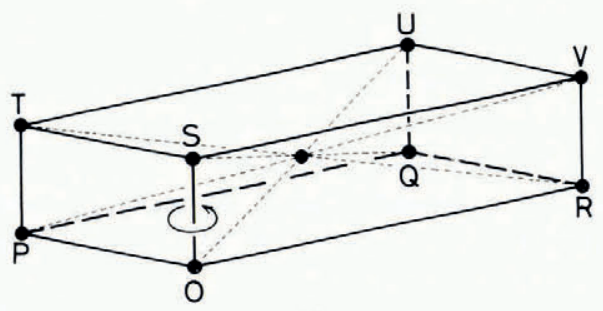

(a)

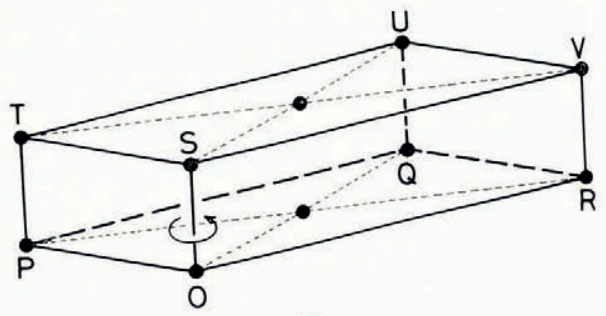

(b)

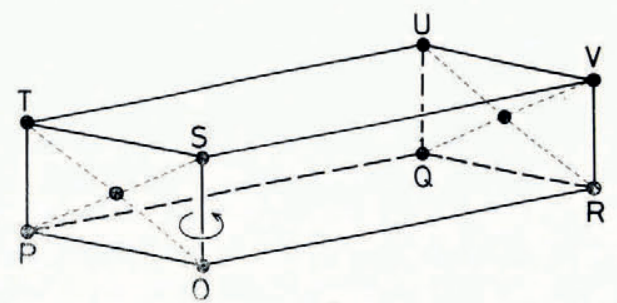

(c)

Fig. I. Coincidence-site lattice composed from simple hexagonal lattices, combinations of even and odd numbers for a pair of $(n, m)$ in Table I give different shapes, $(a)$ for odd $n$ and odd $m,(b)$ odd $n$ and even $m,(c)$ even $n$ and odd $m$. In every case, $O$ is origin and $O S$ is the rotation axis for constructing bicrystals. With the rotation axis $\langle\bar{I} 2 \bar{I} O\rangle, O P=[\bar{m}, o, m, n]$, $O S=\frac{1}{3}[\bar{I} 2 \bar{I} o]$, and $O R=\left[8 n, o, \overline{8 n}, g^{m}\right] / \beta_{\mathrm{I}}$. With the rotation axis $\langle i o \bar{I} o\rangle, O P=\frac{1}{3}\left[\bar{m}, 2 m, \bar{m}, 3^{n}\right], O S=$ $\frac{1}{3}[\mathrm{IO} \overline{\mathrm{I}} \mathrm{O}]$, and $\mathrm{OR}=[8 \mathrm{n}, \overline{\mathrm{I} 6 \mathrm{n}}, 8 \mathrm{n}, \mathrm{gm}] / 3 \beta_{2}$.

It should be noted on Figure I, that a coincidence site lattice is in the body-centred position in the cell for the case of odd numbers of both $n$ and $m$. For the cases of one even and one odd for a pair of $n$ and $m$, face-centred coincidence sites appeared on a pair of end faces of the rectangular prism. In the case of $n=2$ and $m=\mathrm{I}$, the high-density coincidence sites appear on the plane opts as shown in Figure $I(c)$ and this is the plane $(\overline{\mathrm{I}} 2 \overline{\mathrm{I}} \mathrm{I})$ in the case of $\langle\overline{\mathrm{I}} \overline{\mathrm{I}} \mathrm{O}\rangle\rangle$ rotation axis as shown in Table $\mathrm{I}$. This will be referred to again later in association with a special grain boundary of which the behaviour was examined by X-ray diffraction topography.

\section{II-3. Application of the CSL model to ice}

The first attempt to apply the CSL model of grain boundaries to ice was made by Kobayashi and Furukawa ( I 975) to prove that the twelve-branched snow crystals and twin prisms found in ice fog are formed from rotation twins about the (ooor) plane of the ice. In this case, relationships between the $\Sigma$ (they call it multiplicity) and rotation angles $\theta$ are given 
as shown in Table II. If we admit some near-coincidence sites for constructing CSL cells on the basal plane, then the $\Sigma$ decreases as indicated by $\Sigma^{\prime}$ in this table. The rotation angles $60^{\circ}, 3^{8.2^{\circ}}\left(21.8^{\circ}\right), 27.8^{\circ}, 30.6^{\circ}$, and $30.0^{\circ}$ are then the rotations which make the basal composition plane low in energy. A twelve-branched snow crystal shown in Figure 2 exhibits clearly that the misorientation angle between two hexagonals is $22^{\circ}$. Misorientation angles of twelve-branched snow crystals counted from many photographs have several peaks at $18^{\circ}$, $22^{\circ}, 27^{\circ}$, and $30^{\circ}$, and these coincide with the angles of small $\Sigma$ in Table II except for $18^{\circ}$, which is a relatively small peak. Twin prisms of which the rotation angles coincide with those in Table II are also observed.

TABLE II. CSL RELATIONSHIP FOR POSSIBLE COINCIDENCE BOUNDARIES ON (OOOI) IN ROTATION TWINNING (AFTER KobAYASHi AND OTHERs, I976)

\begin{tabular}{|c|c|c|c|c|}
\hline $\begin{array}{c}\text { Rotation angle } \theta \\
\text { deg }\end{array}$ & $\Sigma$ & $\Sigma^{\prime}$ & Twin axes & $\begin{array}{c}\text { Corresponding natural } \\
\text { ice crystals }\end{array}$ \\
\hline 60.0 & $\mathbf{I}$ & & {$\left[\begin{array}{llll}1 & 1 & \overline{2} & 0\end{array}\right]$} & twin prism \\
\hline $3^{8.2}(21.8)$ & 7 & & {$[21 \overline{3} 0]$} & $\begin{array}{l}\text { twist prism } \\
\text { twelve-branched snow }\end{array}$ \\
\hline 27.8 & I3 & & [3 $1 \overline{4} 0]$ & $\begin{array}{l}\text { twist prism } \\
\text { twelve-branched snow }\end{array}$ \\
\hline 30.6 & 97 & 14 & & twelve-branched snow \\
\hline 30.0 & (square) & I I & & \\
\hline
\end{tabular}

$\Sigma^{\prime}$ is the reciprocal density of CSL points when near-CSL junctions are allowed.

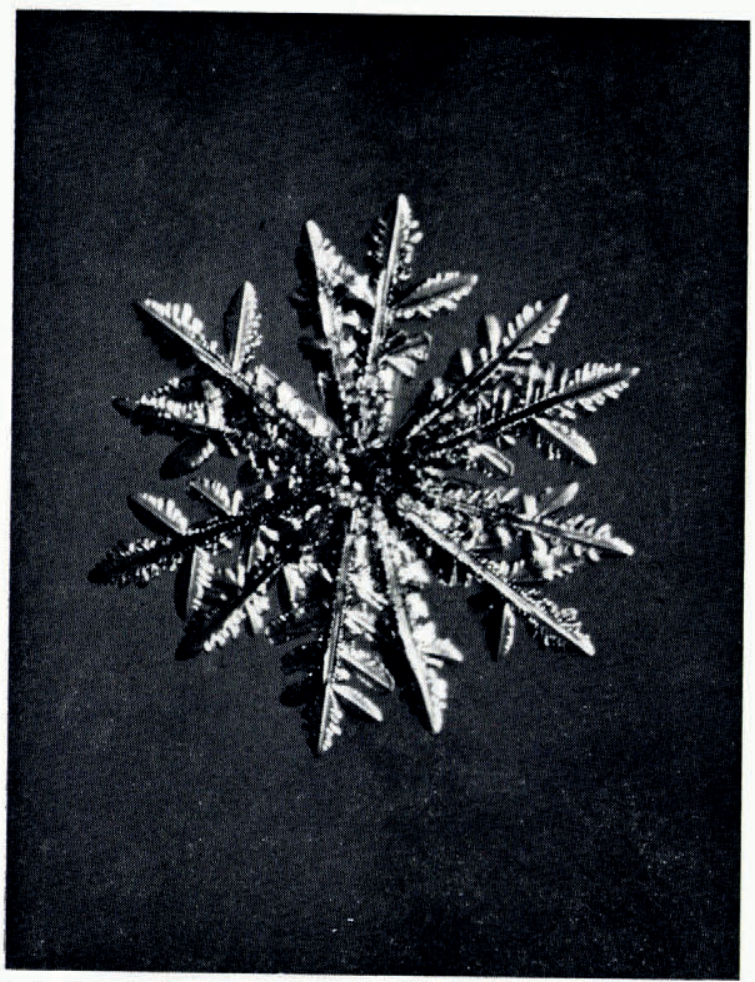

Fig. 2. Twelve-branched snow crystal $\theta=22^{\circ}$ (after Kobayashi and Furukawa, 1975). 
Kobayashi and others (1976) then generalized the CSL concept for extended applications to the structure of polycrystalline snow like combinations of bullets and columns and other peculiar features of natural snowflakes. In the generalized CSL concept, they calculated the angle $\alpha$ between the $c$-axes of two crystals which are in the rotation-twin relationship with a rotation axis perpendicular to a crystallographic plane $\left(h_{1}, h_{2}, \bar{h}_{3}, k\right)$. Since they are only concerned with rotation-twin boundaries, the calculation is limited in the case $\Sigma=\mathrm{I}$, but they "generalized" the CSL model in considering the direction of $\mathrm{O}-\mathrm{O}$ bonds, which makes the case of ice quite different from that of metals.

Although all the lattice points along this composition plane exactly coincide with each other, the orientation of a pair of bond arms extended from each $\mathrm{O}$-atom across the composition plane does not always coincide with each other. Therefore, to judge which planes from arbitrary crystallographic planes $\left(h_{1}, h_{2}, \bar{h}_{3}, k\right)$ can be real twin boundaries, the value of "bond misorientation" angle $\beta$ and that of reciprocal planar density of the coincidence sites $\lambda$ were considered. The smaller the values of $\beta$ and $\lambda$ are, the smaller the boundary energy is. In the case of $\Sigma=\mathrm{I}$, the angle $\alpha$ between the $c$-axes of each component crystal composing $a\left\langle h_{1}, h_{2}, \bar{h}_{3}, k\right\rangle^{*}$ twin is simply given by the equation:

$$
\alpha=180^{\circ}-2 \cos ^{-1} \frac{\sqrt{ } 3}{2}\left(\frac{a}{c}\right)\left[\left(\frac{h_{\mathrm{I}}}{k}\right)^{2}+\left(\frac{h_{2}}{k}\right)^{2}+\frac{h_{1} h_{2}}{k^{2}}+\frac{3}{4}\left(\frac{a}{c}\right)^{2}\right]^{-\frac{1}{2}} .
$$

The angles $\beta$ for all the combinations of each pair of bond arms were then obtained by the stereographic projection method with particular composition planes of low indices which were considered to be interesting in relation to the shape of polycrystalline snow. An example of their calculation is given in Table III, in which the angles $\alpha$ and minimum $\beta$ among various combinations of $\mathrm{O}-\mathrm{O}$ bonds appeared and the planar reciprocal density of CSL $\lambda$ were tabulated for every possible composition plane parallel to the common axis [I I 20 ].

TABLE III. CSL RELATIONSHIPS FOR POSSIBLE $\ll h \mathrm{o} h \gg$ TWINS (AFTER KOBAYASHI AND OTHERs, 1976)

\begin{tabular}{|c|c|c|c|c|}
\hline $\begin{array}{c}\text { Composition } \\
\text { plane }\end{array}$ & $\stackrel{\alpha}{\operatorname{deg}}$ & $\begin{array}{c}\alpha^{\prime}=\underset{1}{ } 180^{\circ}-\alpha \\
\operatorname{deg}\end{array}$ & $\lambda$ & $\begin{array}{c}\beta \\
\operatorname{deg}\end{array}$ \\
\hline IO $\overline{\bar{I}} \mathbf{I}$ & $55 \cdot 7$ & & I. 13 & $9 \cdot 5$ \\
\hline IOĪ 2 & $93 . \mathrm{I}$ & 86.9 & I. 45 & \\
\hline IO $\overline{\mathbf{I}} 3$ & 115.5 & 64.5 & 1.87 & 4.0 \\
\hline $10 \overline{\mathrm{I}} 4$ & 129.3 & $5^{0.7}$ & 2.34 & II.o \\
\hline $10 \overline{1} 5$ & 138.5 & $4^{1} \cdot 5$ & 2.82 & 2.0 \\
\hline $10 \overline{1} 6$ & I 45.0 & 35.0 & $3 \cdot 3^{2}$ & $4 \cdot 5$ \\
\hline $10 \overline{\mathbf{1}} 7$ & 149.7 & 30.3 & 3.83 & 9.0 \\
\hline $10 \overline{1} 8$ & 153.4 & $26 . \overline{6}$ & 4.34 & 12.0 \\
\hline $20 \overline{2} \mathrm{I}$ & 29.6 & & 2.07 & 8.5 \\
\hline $20 \overline{2} 3$ & 76.8 & & 2.55 & 3.0 \\
\hline $20 \overline{2} 5$ & 105.7 & $74 \cdot 3$ & $3 \cdot 31$ & 2.0 \\
\hline $20 \overline{2} \overline{7}$ & 123.2 & 56.8 & 4.20 & 9.0 \\
\hline $30 \overline{3}^{1}$ & 20.0 & & 3.05 & 12.5 \\
\hline $30 \overline{3}^{2}$ & $3^{8} 8.8$ & & 3.18 & o.o \\
\hline $30 \underline{3} 4$ & 70.3 & & 3.67 & 0.0 \\
\hline 3035 & 82.7 & & 4.00 & 7.0 \\
\hline $30 \overline{3} 7$ & 101.9 & 78.1 & 4.76 & 6.5 \\
\hline 3038 & 109.2 & 70.8 & 5.18 & 0.0 \\
\hline $40 \overline{4} 1$ & 15.0 & & 4.03 & $9 \cdot 5$ \\
\hline $40 \frac{4}{4} 3$ & 43.2 & & $4 \cdot 30$ & 4.5 \\
\hline $40 \frac{7}{4} 5$ & 66.9 & & 4.79 & 2.5 \\
\hline $40 \frac{7}{4}$ & 85.5 & & 5.45 & 9.0 \\
\hline 5051 & I2. I & & 5.03 & 8.0 \\
\hline $50 \overline{5} 2$ & 23.9 & & 5.11 & 3.0 \\
\hline
\end{tabular}

* The symbol $\ll \gg$ means a twin axis perpendicular to the plane $\left\{h_{1}, h_{2}, \bar{h}_{3}, k\right\}$. 
If we consider that smaller values should be taken with $\beta$ and $\lambda$ for a real twin boundaries, 《IOĪO may be predicted. Figure 3 illustrates a section of the $《 30 \overline{3} 4\rangle$ twin on the plane of ( I $1 \overline{2} 0$ ). Open and closed circles represent the position of $\mathrm{O}$-atoms on two adjacent planes parallel to $\left(\mathrm{I}_{\overline{2}} \mathrm{O}\right)$. Bondings of $\mathrm{O}-\mathrm{O}$ atoms in twinning positions at the boundary $(30 \overline{3} 4)$ indicated by dashed lines are perfect at such sites as indicated by arrows and this projection gives $\beta=\mathrm{o}$ in Table III as the minimum value of various $\beta$ s. Figure 4 is a frequency histogram of measured angles between the $c$-axes of each component in a combination of bullets (columns conically terminated) lying on the same plane of photomicrographs collected from various sources. Peaks at around $90^{\circ}, 70^{\circ}, 55^{\circ}$ correspond to $\left.\langle\operatorname{IO} \overline{\mathrm{I}} 2\rangle, 《 30 \overline{3} 4\right\rangle$ or $\langle 30 \overline{3} 8 》$, and 《IOĪO》twins among the predicted ones stated above. From these coincidences, Kobayashi and others concluded that such special shapes of snow as a combination bullets and other assemblages of twinned columns and scrolls originated from twinned seeds and then each component grew under the favourable circumstances for prism growth. The real mechanism of twinning at the very initial stage of nucleation is not known yet.

Twin relations are also found between interlocked crystals in large-grained glacier ice which exhibits the diamond fabric pattern (Matsuda and Wakahama, I977). They measured the rotation angles both of $c$-axes $(\tau)$ and $a$-axes $\left(\alpha_{i j}\right)$ between every pair of adjacent grains, and obtained the combination of values to be satisfied by any $180^{\circ}, 120^{\circ}, 90^{\circ}$, and $60^{\circ}$ twins. However, they did not consider the results using the CSL concept and therefore the structure and origin of twin boundaries is not clear.

\section{ENERGETICS OF GRAIN BOUNDARIES IN ICE}

Grain-boundary energy or interface energy of ice was determined experimentally first by Ketcham and Hobbs (1969). The method they adopted was to measure the angle of grain-

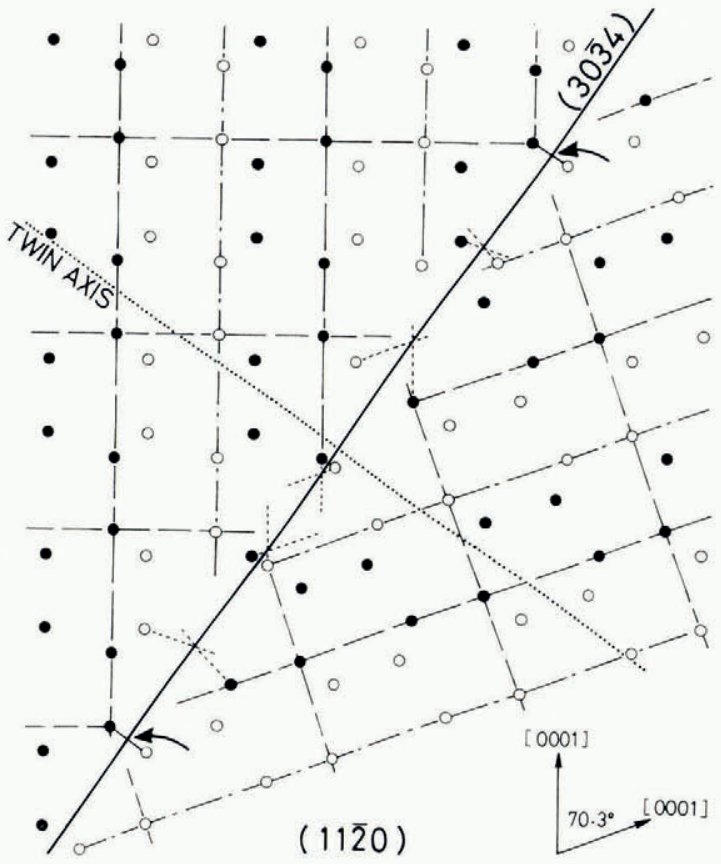

Fig. 3. Illustration of a bonding structure along a composition boundary in a $\ll 30 \overline{3} 4 \gg$ twin. Bondings are perfect at coincidence sites indicated by arrows (after Kobayashi and others, 1976). 


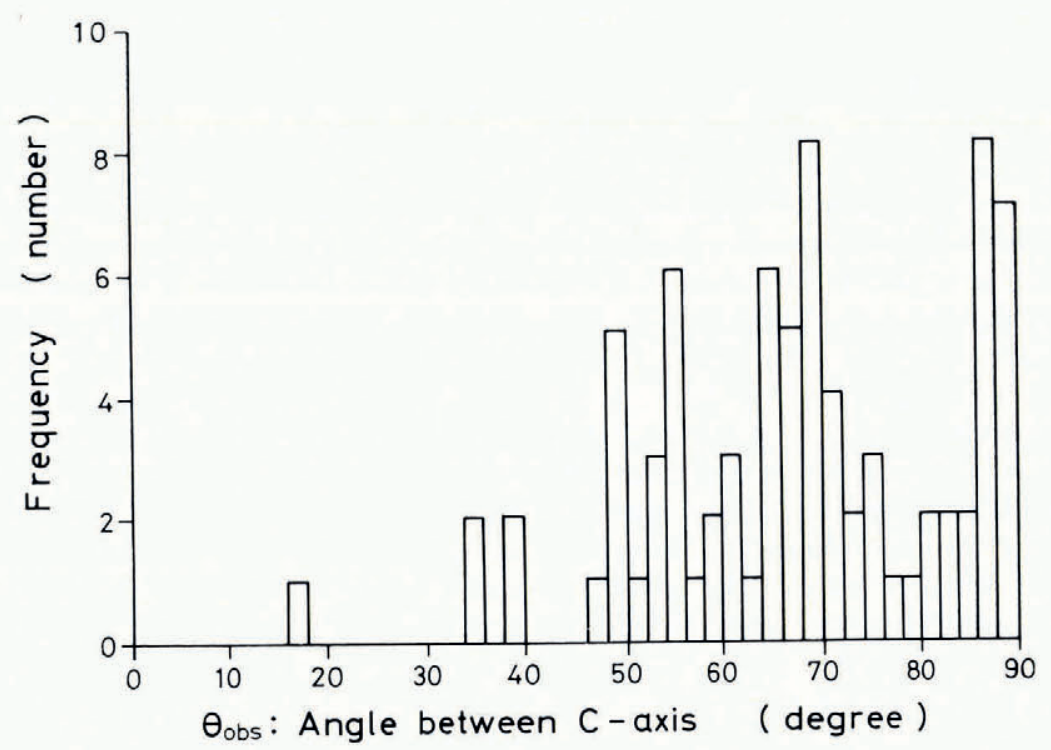

Fig. 4. A frequency histogram of measured angle between the c-axes of each component in a combination of bullets lying on the same plane of photographs (after Kobayashi and others, 1976).

boundary grooves as shown in Figure 5. Such a groove appears at the intersection of a grain boundary with the surface of ice exposed to its saturated water vapour in equilibrium. If the groove angle at the bottom is $\theta_{\mathbf{v s}}$, the balance of the surface-tension forces shown in Figure 5 requires the following equation,

$$
\frac{\sigma_{\mathrm{gb}}}{\sigma_{\mathrm{vs}}}=2 \cos \left(\theta_{\mathrm{vs}} / 2\right) .
$$

For the determination of $\sigma_{\mathrm{gb}}$, it is necessary to measure the angle $\theta_{\mathrm{vs}}$, which is also needed for the determination of $\sigma_{\mathrm{vs}}$. To measure the angle $\theta_{\mathrm{vs}}$, they coated the surface of ice in equilibrium with a solution $(5 \%$ by weight Formvar/ethylene dichloride) to take a replica of the shape of the grooves. After the solvent had evaporated, the replica film was carefully peeled off and lightly silvered, and then it was examined under an interference microscope. Contours of the interference stripes at the groove gave the slope and consequently the angle $\theta_{\mathrm{vs}}$.

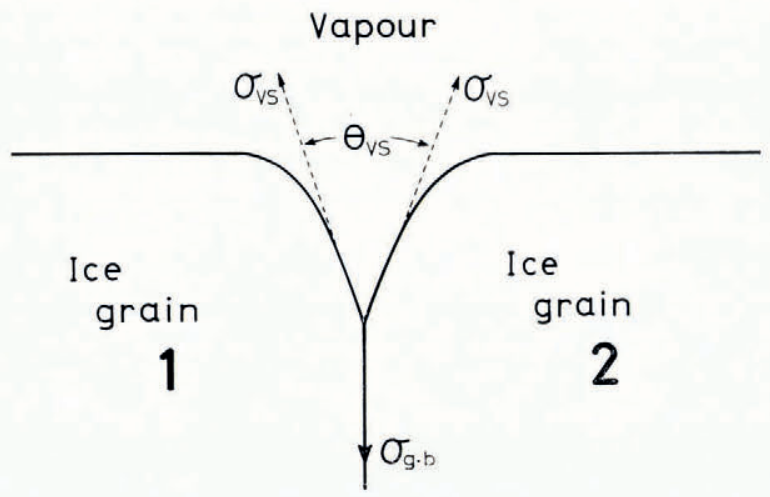

Fig. 5. Section of a groove between two grains of ice in equilibrium with water vapour. 
For the estimate of $\sigma_{\mathrm{vs}}$, it is necessary to know the value of $\theta_{1 \mathrm{~s}}$ in addition to $\theta_{\mathrm{vs}}$ and also the contact angle $\phi$ of water on ice, where $\theta_{1 \mathrm{~s}}$ is the groove angle as in Figure 5 when the surface of ice is in contact with water instead of the saturated water vapour. Both of these quantities were also determined carefully by themselves and the results are given as follows:

$$
\begin{aligned}
\sigma_{\mathrm{Is}} & =(33 \pm 3) \mathrm{mJ} \mathrm{m}^{-2}, \\
\sigma_{\mathrm{vs}} & =(\mathrm{I} 09 \pm 3) \mathrm{mJ} \mathrm{m}^{-2}, \\
\sigma_{\mathrm{gb}} & =(65 \pm 3) \mathrm{mJ} \mathrm{m}^{-2} .
\end{aligned}
$$

The value of $\sigma_{\mathrm{ls}}$ is not directly related to the grain-boundary energy but it was obtained from the measurement of $\theta_{\mathrm{ls}}$. They measured the angle $\theta_{\mathrm{vs}}$ and $\theta_{\mathrm{ls}}$ in various cases of different misfit angles between two adjacent grains to determine whether there existed any anisotropy at those angles. They found a tendency of increasing $\theta_{\mathrm{ls}}$ only at small angles between the $c$-axes of two grains, but practically no anisotropy with $\theta_{\mathrm{vs}}$. The limits of error indicated above are those deduced from the scatter of the measured values.

Suzuki (1970) and Suzuki and Kuroiwa (1972) adopted a new method in which the grooved ice surface was covered by a thin foil $(0.3 \mu \mathrm{m}$ in thickness) of brass to avoid any chemical modification of the ice surface by the replica solution. The thin foil was carefully put on the ice surface and a slight pressure was applied to the foil surface with a clean silk cloth to ensure the tight adhesion between the foil and the ice surface so that the shape of the groove can be detected precisely using an interference microscope. They compared the values of $\theta_{\mathrm{vs}}$ measured by this method with those measured by the replica method and found that the former were always smaller than the latter. They attributed this systematic difference of the values of $\theta_{\mathrm{vs}}$ to the attacking by ethylene dichloride of the ice surface, which might increase the depth of grooves. Although they found variations of the value $\theta_{\mathrm{vs}}$ with respect to the misorientation angle of $c$-axes or of $a$-axes and calculated those of the grain-boundary energy, no interpretation was given on those variations. In the calculation of grain-boundary energy, they used theoretical values of the surface energy $\sigma_{\mathrm{vs}}$ obtained by Reuck (1957). Since this is approximately ro to $20 \%$ higher (differing with basal and prism planes) than that determined experimentally as above, and the angle $\theta_{\mathrm{vs}}$ is smaller in the case of the thin foil method than the replica method, values of the grain-boundary energy obtained by Suzuki ranged between 60 to $100 \mathrm{~mJ} \mathrm{~m}^{-2}$.

Suzuki (I970) also measured the relative magnitude of the grain-boundary energy by observing the equilibrium angle of the triple node of the boundary, using the relationship

$$
\frac{\sigma_{23}}{\sin \phi_{1}}=\frac{\sigma_{13}}{\sin \phi_{2}}=\frac{\sigma_{12}}{\sin \phi_{3}}
$$

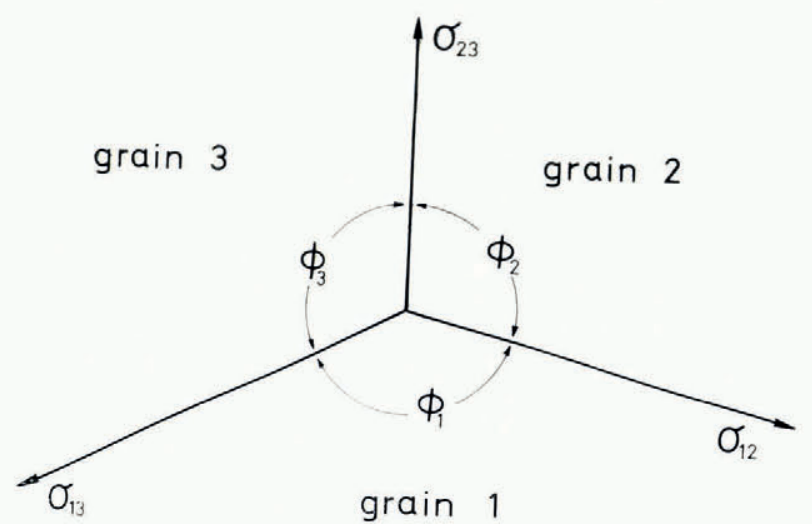

Fig. 6. Triple no de of three grain boundaries of ice in equilibrium. See Equation (8). 
which holds between the three grain-boundary energies $\sigma_{23}, \sigma_{13}$, and $\sigma_{12}$ with respect to the angle $\phi_{1}, \phi_{2}$, and $\phi_{3}$ as indicated in Figure 6. If the orientation relation between two particular grains is fixed, for example between $\mathrm{I}$ and 2, then we can determine the values of $\sigma_{23}$ and $\sigma_{31}$ relative to $\sigma_{12}$ from the measurements of angles $\phi_{1}, \phi_{2}$, and $\phi_{3}$.

In his experiments, the misorientation angle between the $c$-axes of grain I and 2 was fixed at $50^{\circ}$ and the direction of $c$-axis of grain 3 was varied. The relative values $R=\sigma_{23} / \sigma_{12}$ or $\sigma_{13} / \sigma_{12}$ are plotted against the misfit angles between either grain $\mathrm{I}$ or 2 and grain 3 on Figure 7. He examined these data with a theoretical expectation, derived from Equation (I),

$$
\frac{R}{\theta}=R_{0}[A-\log \theta]
$$

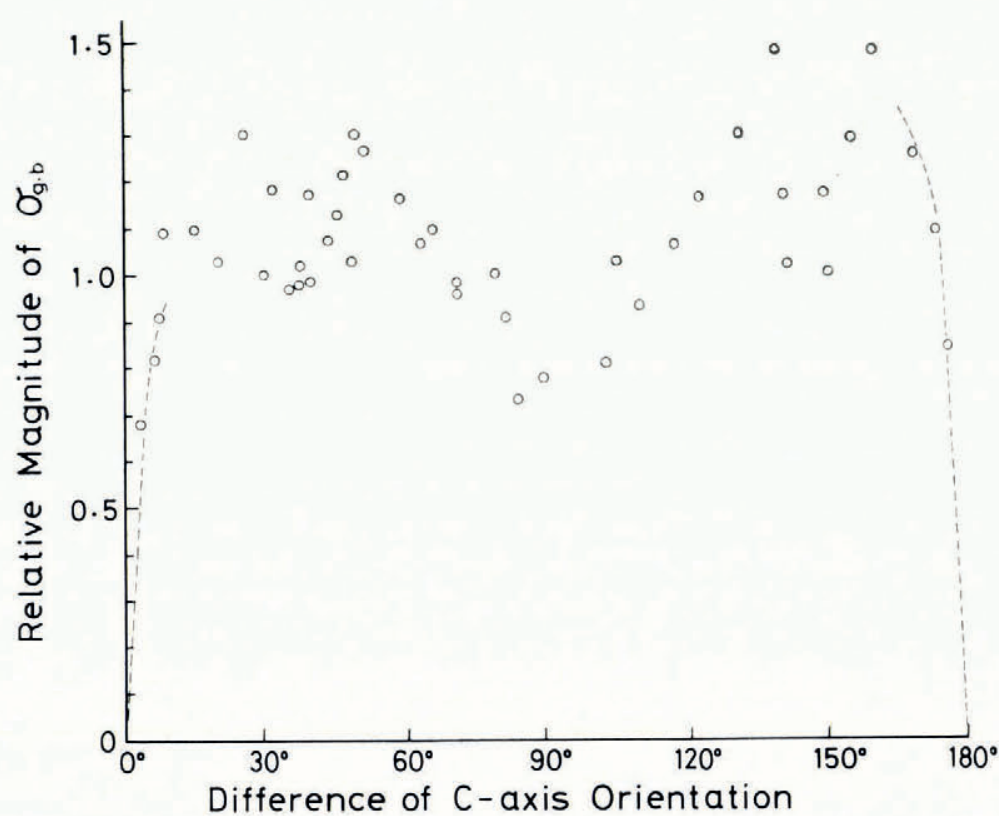

Fig. 7. Relative values of grain-boundary energy with respect to misorientation angles $\theta$ between the c-axes of the two adjacent grains of ice. Boundary energy at $\theta=50^{\circ}$ was taken as standard (after Suzuki, 1970).

which was derived from the dislocation model of small-angle boundaries, and found that this equation held between $0^{\circ}$ and $20^{\circ}$ for the misorientation angle $\theta$.

Although he did not mention it, Figure 7 seems to show that there are several cusps of grain-boundary energy for larger $\theta$, at approximately $40^{\circ}, 90^{\circ}$ and $145^{\circ}$. Since the $c$-axis of every grain lay parallel to the specimen surface, these angles corresponds to misfit angles which frequently appear for small $\Sigma$ as tabulated in Table I, for example $86.8^{\circ}$ around $\langle\overline{\mathrm{I}} \mathbf{2} \overline{\mathrm{I}} \mathrm{O}\rangle$ axis for a boundary plane $(\mathrm{IO} \overline{\mathrm{I}} 2)$ with $\Sigma=\mathrm{I} 7$, and $34.05^{\circ}$ around $\langle\mathrm{IO} \overline{\mathrm{I}} \mathrm{O}\rangle$ axis for a boundary plane $(\overline{\mathrm{I}} 2 \overline{\mathrm{I}} \mathrm{I})$ with $\Sigma=35$. More precise experiments of this kind should be done with full knowledge of the orientation relation between two grains before reaching any definite conclusion on the dependence of the grain-boundary energy in ice on the misfit angle. 


\section{Observations of GRAin Boundaries}

X-ray diffraction topography has been successfully adopted to observe grain boundaries in ice. This method has an advantage for ice in the sense that it does not require holding a specimen in vacuum as electron microscopy does. Although its resolution is much less (c. Io $\mu \mathrm{m}$ ) than that of electron microscopy, X-ray diffraction topography has another advantage in that the field of observation is very wide, being up to several tens of millimetres. Although theories of X-ray diffraction images of dislocations in crystal have been developed extensively in the last decade, no exact theory exists for images of grain boundaries. However, in principle, X-ray diffraction is distorted quite sensitively by strain fields in the crystal, and any strain field which occurred on or near the boundary could be detected by this method. To make it possible to observe any characteristic images of grain boundaries, the lattice dislocation density in the grains should be low enough not to disturb the images of boundaries.

Figure 8(a) and (b) shows a pair of X-ray topographs which were taken with the (II $\overline{2} \mathrm{O}$ ) reflection for both grains of a bicrystal which had a tilt grain boundary (misfit angle $34^{\circ}$ around $\mathrm{a}\langle\mathbf{\mathrm { I }} \overline{\mathrm{I}} \mathrm{O}\rangle$ rotation axis) between them. Pendellösung fringes on both topographs reveal that the area $\mathrm{ABCD}$ corresponds to a grain boundary which crosses the surface of the specimen at a very acute angle as illustrated in Figure 8(c). Since the bicrystal was grown very successfully, the density of lattice dislocations was in this case very low, probably $<$ io $\mathrm{cm}^{-2}$, and they did not disturb observation of any particular images on the boundary. Using this specimen, Hondoh and Higashi (1978) tried to observe what happened on the boundary when the specimen was stressed. Since the results will be presented in another paper at this symposium, only the essential results will be briefly described here.

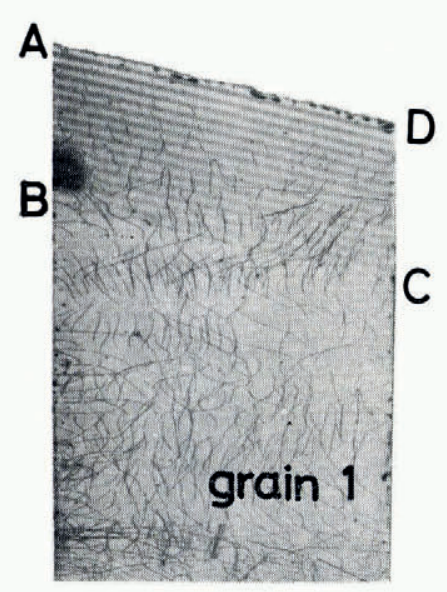

(a)

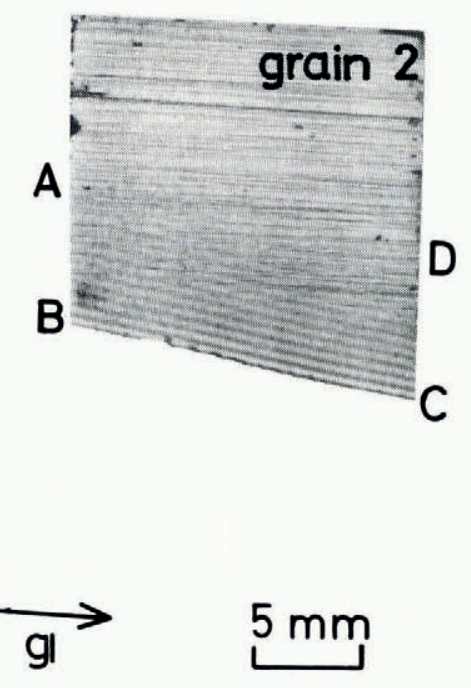

(b)

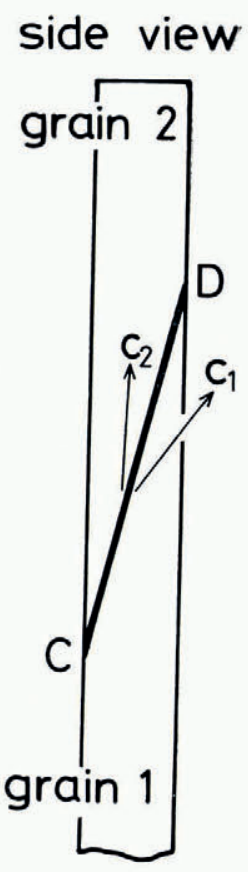

(c)

Fig. 8. A pair of X-ray diffraction topographs taken with $(I I \overline{2} O)$ reflection for grain $I(a)$ and $2(b)$ between which a boundary lies as shown in (c) (after Hondoh and Higashi, 1978). 
The line images appearing on the boundary disappear when the specimen is aged for several hours or more and appear again at the same sites when the specimen is stressed again. The disappearance of the line images means that the strain concentration along the lines has relaxed after the ageing. However, such repeated appearance at the same sites indicate that some faults must exist at these sites even though they cannot be detected by X-ray topography. We propose that the line images are due to stress concentrations at steps on the grain boundary. If the real boundary deviates a little from any crystallographic plane of densely packed coincident sites, it should be composed of such a CSL boundary with facets and steps which adjust to a small angle of deviation. Strengthening of the line images due to stressing specimens can be explained by the increased strain around steps with increased stress. This explanation tacitly postulates that grain-boundary sliding in polycrystalline ice takes place easily at such CSL boundary planes. The fact that the lattice dislocation density near this boundary did not change, nor did any grain-boundary dislocations appear on the boundary, seems to support this postulate.

\section{Movement of the LARge-Angle grain boundaries}

\section{V-I. Movement of the boundary due to capillary force}

Mobilities of large-angle grain boundaries in ice were studied in two different cases, in one of which the driving force was caused by the capillary force on a curved grain boundary, and in the other the driving force was the strain energy stored in a bent single crystal. For the former case, the following experimental method, which was developed by Sun and Bauer (1970[b]) for their study of $\mathrm{NaCl}$, was used. If we anneal a bicrystal specimen as shown in Figure 9, the tilt boundary normal to a surface A, which originally subtended an acute angle $\alpha$ with a free surface $\mathrm{B}$, bent towards the right so as to reduce the area of the boundary or to make the angle $\alpha$ less acute. According to Sun and Bauer's analysis for the capillary force due to local curvature at the intersection of the boundary to the surface B (Sun and Bauer, I97o[a]), the relation between the distance of movement of the intersection $a$ measured from its original point and time $t$ is

$$
a^{2}=\kappa t,
$$

where $K=2 M \gamma f(\alpha), M$ denotes the mobility, $\gamma$ the boundary energy, and $f(\alpha)$ is a factor which magnifies the driving force due to the magnitude of $\alpha$ or the local curvature at the intersection of the boundaries with the surface. Plotting the square of the measured $a$ as ordinate and the elapsed time $t$ as abscissa of a graph, the slope of the initial curve gives $K$ and consequently $M \gamma$ with a correction of $f(\alpha)$ to be given numerically.

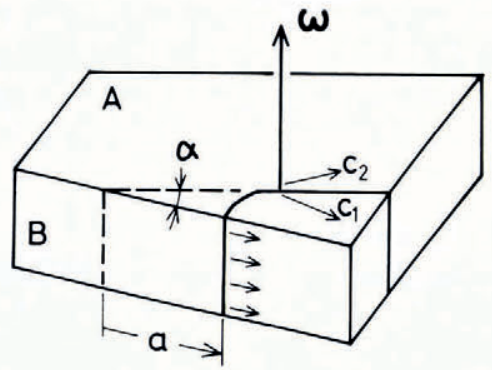

(a)

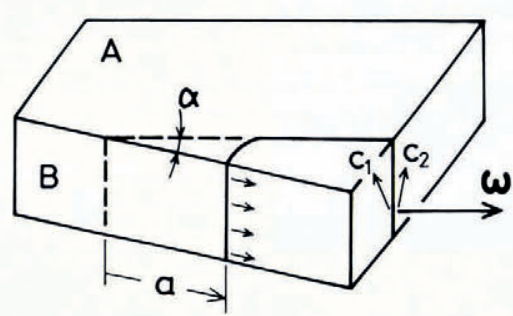

(b)

Fig. 9. Schematic illustration of a specimen for experiments by Sun and Bauer's method: $(a) \omega_{\perp}$ and $(b) \omega_{\|}($Hondoh, unpublished). 
Using this method, Hondoh (unpublished) carried out experiments to measure the mobility of tilt boundaries rotated around a [IO $\overline{\mathrm{I}} \mathrm{O}]$ axis in bicrystals of ice. Two types of specimens were prepared from artificially grown bicrystals with controlled tilt angles between their $c$-axes. In one the crystal was cut to have its face of broadest area perpendicular to the rotation axis $\omega$ and denoted as $\omega_{\perp}$ (Fig. 9(a)) and in the other it was parallel to $\omega$ and denoted as $\omega_{\|}$(Fig. 9 (b)). He found that the grain boundary in $\omega_{\|}$specimens moves much faster than

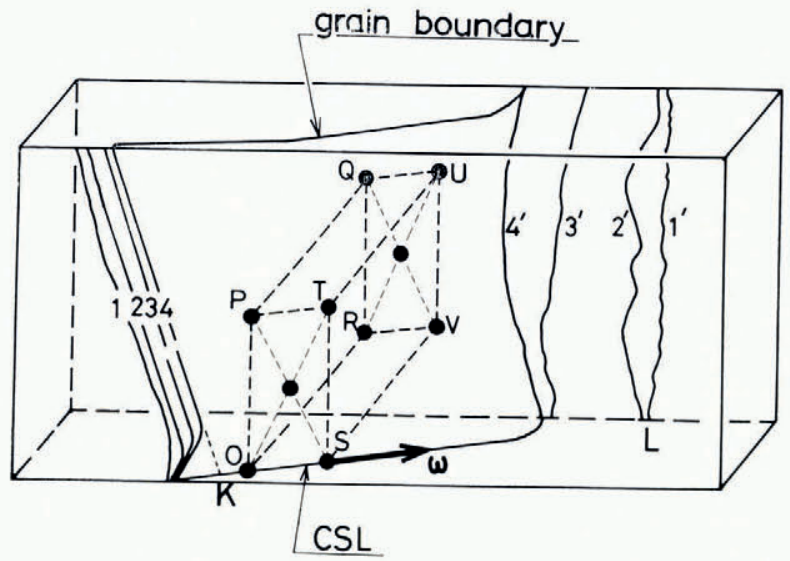

(a)

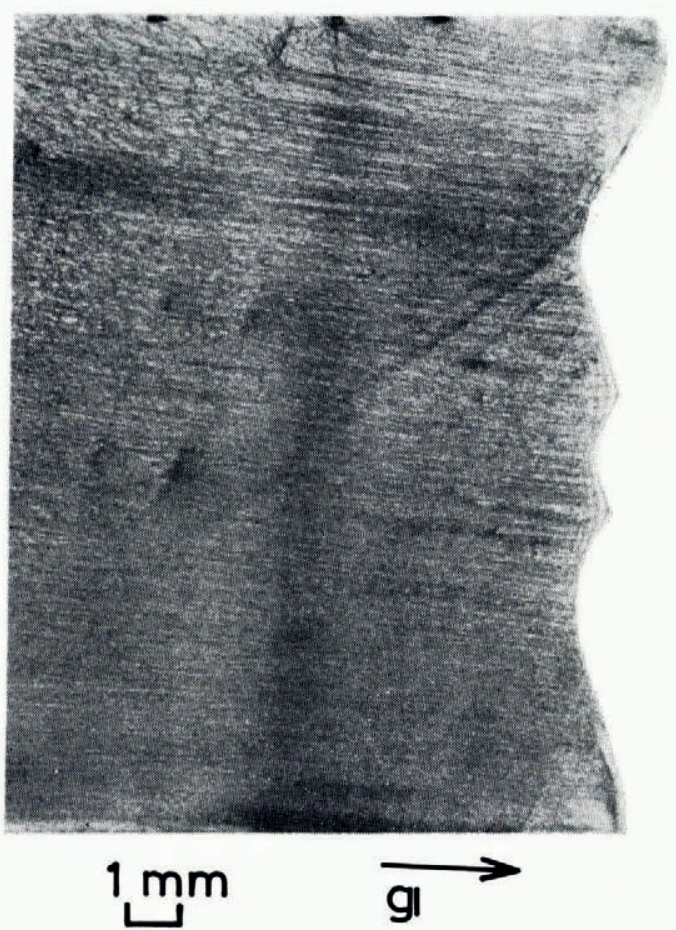

(b)

Fig. 10. Tracings from $X$-ray topographs of a boundary migrating under the action of capillary forces (a), and an example of wavy intersections of the fast-moving boundary on a topograph $(b)$. Time intervals between numbered lines in $(a)$ are: $66 \mathrm{~h}$ between $\mathrm{I}$ and $2\left(\right.$ treatment at $\left.-20^{\circ} \mathrm{C}\right)$, 7o $\mathrm{h}$ between 2 and $3\left(-5^{\circ} \mathrm{C}\right), 5^{\circ} \mathrm{h}$ between 3 and $4\left(-5^{\circ} \mathrm{C}\right)$. 
in $\omega_{\perp}$ specimens, sometimes even by a factor of several tens. This anisotropy of the mobility of grain boundaries in ice could be also interpreted with the CSL concept. In our recent studies of grain-boundary migration with the help of X-ray diffraction topography, ${ }^{*}$ the movement of two intersections of the boundary $\left(\alpha \approx 34^{\circ}\right.$ around 〈I $\left.\left.\overline{1} \overline{0}\right\rangle\right)$ with opposite surfaces of a thin specimen were observed. Due to a slight bend of the boundary in the specimen, one of the intersections happened to make approximately $63^{\circ}$ with the rotation axis $\omega=\langle\mathrm{IO} \overline{\mathrm{I}} \mathrm{O}\rangle$ while another was perpendicular to $\omega$ as are indicated in Figure $\mathrm{IO}(\mathrm{a})$ by $\mathrm{K}$ and $\mathrm{L}$ respectively. Positions of intersections of these two kinds obtained from X-ray diffraction topographs taken intermittently are designated by sequential numbers in Figure ro(a). Apparently, the migration velocity of the intersection perpendicular to $\omega$ is faster than that making $63^{\circ}$ to $\omega$, and by Sun and Bauer's analysis described above, the values of $M \gamma$ obtained from these data were $(6$ to 17$) \times 1^{-8} \mathrm{~cm}^{2} \mathrm{~s}^{-1}$ for the former and $0.2 \times 10^{-8} \mathrm{~cm}^{2} \mathrm{~s}^{-1}$ for the latter. As can be seen clearly in Figure ro(b), the former intersection had a wavy (or stepped) shape while the latter exhibited clear facets.

As was described at the end of Section II-2 and also was shown in Table I, the plane most densely packed with coincidence sites is $(\overline{\mathrm{I}} 2 \overline{\mathrm{I}} \mathrm{I})$ in the case of $\alpha=34^{\circ}$ around $\langle\mathrm{IO} \overline{\mathrm{I}} \mathrm{O}\rangle$. Therefore, the unit cell of the CSL of Figure $\mathrm{I}(\mathrm{c})$ can be transposed in such a way as drawn by dotted lines in Figure $\mathrm{IO}(\mathrm{a})$ as os is the rotation axis $\omega$. Then, the actual direction of the fastmoving intersection is parallel to ST and that of the slow-moving intersection is parallel to SP which subtends $63^{\circ}$ with os. It has been found from other experiments* that a CSL boundary of the same kind exhibits facets in three directions of os, oT, and sP, each of which is a direction of the most closely packed coincidence sites on this $(\overline{\mathbf{I}} 2 \overline{\mathrm{I}} \mathrm{I})$ plane. As can be seen in Figure Io(a), the actual moving plane of the boundary makes a very acute angle with a normal to the plane OsтP except at the very initial stage of the movement; it should extend nearly parallel to the long direction of the CSL unit cell. Since the length of this direction is nearly ten times larger than that of the sides os, it is not so essential whether the facet planes coincide or not with the planes, OSVR, OTUR, and SPQv. The essential facts are that the actual slowmoving plane in the case of Figure $\mathrm{IO}(\mathrm{a})$ is nearly parallel to PS, and is parallel to so in the case of Figure $9(\mathrm{a})$, while the fast-moving plane in both Figure $10(a)$ or in Figure $9(\mathrm{~b})$ is parallel to ST. The fast-moving intersection exhibits wavy facets as shown in Figure ro(b), and this suggests that the fast-moving plane, which may be parallel to a non-facet plane like sTUV $(\perp \omega)$ should be composed of small segments of facets parallel to ot or sP and many steps between them. This kind of plane may be able to move faster by the movement of kinked steps or ledges than the very smooth facet planes, as Gleiter (ig69[a], [b]) suggested for metals. The facets which appeared on the topograph of Figure $10(b)$ are much larger than those mentioned by Gleiter, but this could be because the observation in ice were made at a very high homologous temperature. The mobility of the faceted boundary plane should be small due to the lack of steps.

\section{$\mathrm{V}-2$. Movement of the boundary of recrystallized grains}

Another kind of experiment on grain-boundary migration was carried out using the phenomenon of growth of recrystallized grains in bent single crystals of ice (Fukuda and others, 1977). When a single crystal bar of ice of which the top and bottom surfaces are parallel to its crystallographic (OOOI) plane is subjected to three-point bending around $\langle\mathrm{I} \overline{\mathrm{I}} \overline{2} \mathrm{O}\rangle$ and annealed at a temperature near $0^{\circ} \mathrm{C}$, recrystallization takes place from the top sharp bend.

Growth of a recrystallized grain was observed with a thin specimen between crossed polaroids, and its progress was recorded on a time-lapse movie film. Figure I I(a) is an

* Paper by T. Hondoh and A. Higashi entitled "Anisotropic migration and faceting of high-angle grain boundaries in ice bicrystals", in preparation. 


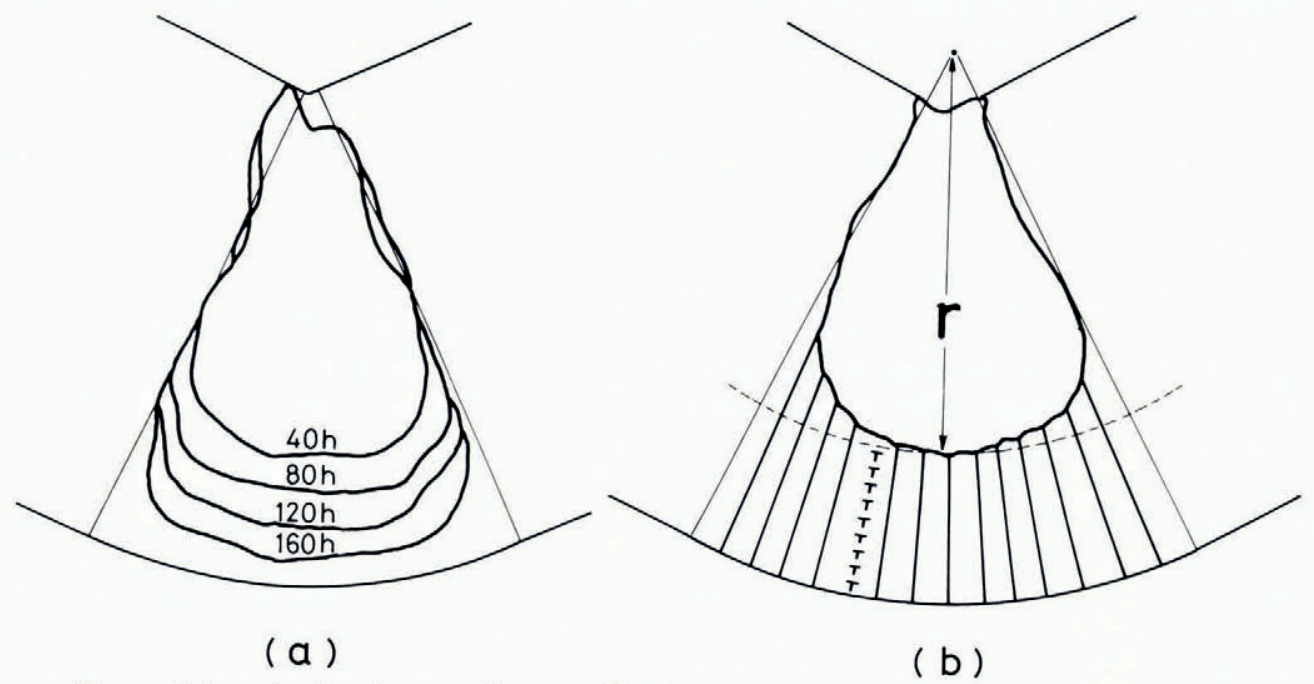

Fig. II. Traces of the moving boundary around a recrystallized grain in a bent single crystal of ice (a), and an illustration to show the driving forces in such a case $(b)$.

example of this process analysed from the film. When the growth process reached a steady state, the area of the recrystallized part $S$ increased linearly with time $t$, that is to say

$$
S=k t+C,
$$

where $k$ is the areal speed of grain growth. Since the grain grew in similar figures with a common vertical angle, the linear velocity $v$ of growth front (boundary) is derived as

$$
v=\frac{k}{2 \beta} \frac{\mathrm{I}}{r},
$$

where $\beta$ is a constant to be determined empirically from the shape of recrystallized grain and $r$ is its modified diameter as shown in Figure $\mathrm{II}(\mathrm{b})$.

Since in this case the driving force $P$ for the movement of the grain boundary should be the stored strain energy in the bent portion due to the assemblage of small-angle boundaries as shown schematically in Figure i I (b), it can be expressed as follows for a unit length of the boundary:

$$
P=\left\{\frac{\mu b}{4 \pi(\mathrm{I}-\nu)}(A+\log n)-\frac{\gamma}{\alpha}\right\} \frac{\mathrm{I}}{r} .
$$

This equation is obtained from the Equation ( $\mathrm{I}$ ) in Section II-I, assuming that there exist $n$ small-angle boundaries of equal tilt angle in unit vertical angle of the recrystallized fan. The capillary term $\gamma / \alpha r$ due to the boundary energy $\gamma$ is in this case a small negative term compared to the stored strain energy and its inverse proportionality with $r$ is obtained from the empirical fact that the radius of curvature of the boundary was proportional to $r$ with constant of proportionality $\alpha$.

The mobility $M$ of the boundary is then given by inserting Equations (12) and (13) in the equation of its definition as follows,

$$
\begin{aligned}
M & =v / P \\
& =\frac{k}{2 \beta}\left[\frac{\mu b(A+\log n)}{4 \pi(\mathrm{I}-\nu)}-\frac{\gamma}{\alpha}\right]^{-1} .
\end{aligned}
$$


Numerical calculations with values of $k, \beta$, and $\alpha$ obtained by experiment and with an assumption of $n=100$ to $\mathrm{I}$ ooo gave the mobility $M$ in a range of $(3$ to 9$) \times 10^{-10}$ $\mathrm{cm}^{-3} \mathrm{dyn}^{-1} \mathrm{~s}^{-1}\left((3\right.$ to 9$\left.) \times 10^{-11} \mathrm{~m}^{3} \mathrm{~N}^{-1} \mathrm{~s}^{-1}\right) . \gamma$ was taken as $70 \mathrm{~mJ} \mathrm{~m}^{-2}$ (Suzuki, 1970) in this case. This value of $M$ roughly coincides with that obtained from the value of $M \gamma$ for the faster-moving boundary with Sun and Bauer's method as described in the last sub-section.

\section{Conclusion}

In this review paper, I have shown that grain-boundary problems in ice have been recently cast in a new light both theoretically and experimentally. Theoretically, the structures of grain boundaries in ice have been analysed with the coincidence-site lattice (CSL) concepts through different methods of approach. Although the theory of CSL for ice crystals is not yet complete, such analyses have succeeded in explaining some special crystal shapes of natural snow, results of energy experiments, and X-ray diffraction topographic observations of grain boundaries. Deeper considerations on the theory either in geometry or energetics are necessary.

Experimentally, methods of measuring energies have been developed, but it is still necessary to measure the grain-boundary energy in conjunction with misorientation angles between two adjacent grains to supplement theoretical considerations. X-ray diffraction topography has been successfully used to observe microscopically the structure and behaviour of grain boundaries in ice. It is necessary to construct a theory of diffraction with grain boundary defects, as well as to accumulate more experimental data with this method, to clarify mechanisms of grain-boundary migration and sliding.

\section{Acknowledgements}

I am most grateful to Mr T. Hondoh for providing unpublished material for writing this paper. I am also indebted to Dr T. Kobayashi, Dr A. Fukuda, and Mr T. Hondoh for many helpful discussions.

\section{REFERENCES}

Bollmann, W. A. 1970. Crystal defects and crystalline interfaces. Berlin, Springer-Verlag.

Bruggeman, G. A., and others. 1972. Coincidence and near-coincidence grain boundaries in HCP metals, by G. A. Bruggeman, G. H. Bishop and W. H. Hartt. (In Hu, H., ed. The nature and behavior of grain boundaries. New York, Plenum Press, p. 83-122.)

Chadwick, G. A., and Smith, D. A., ed. 1976. Grain boundary structure and properties. London, Academic Press.

Chaudhari, P., and Matthews, J. W., ed. 1972. Grain boundaries and interfaces. Proceedings of the international conference on the structure and properties of grain boundaries and interfaces, Yorktown Heights, New York, 23-25 August 197 I. Amsterdam, North-Holland Publishing Co.

Fukuda, A., and Higashi, A. r973. Dynamical behavior of dislocation in ice crystals. Crystal Lattice Defects, Vol. 4, No. 3, p. 203-10.

Fukuda, A., and others. 1977. Sosei-henkei o uketa kōri-tankesshō-chu no saikesshoryu no seichō [Growth of the recrystallized grain in a plastically deformed ice single crystal]. [By] A. Fukuda, Y. Igarashi, K. Kitakizaki. Seppyō, Vol. 39, No. 3, p. 109-16.

Gleiter, H. r $969[\mathrm{a}]$. The mechanism of grain boundary migration. Acta Metallurgica, Vol. 17, No. 5, p. 565-73.

Gleiter, H. I969[b]. Theory of grain boundary migration rate. Acta Metallurgica, Vol. 1 7, No. 7, p. 853-62.

Higashi, A., and Sakai, N. r96r. Movement of small angle boundary of ice crystal. Journal of the Physical Society of Japan, Vol. i6, No. I I, p. 2359-6o.

Hondoh, T. Unpublished. Kōri no kesshō-ryukai no idō ni kansuru kisoteki kenkyū [Fundamental studies on the migration of grain boundaries in ice]. [Thesis for Master of Engineering, Graduate School of Hokkaido University, I974.]

Hondoh, T., and Higashi, A. 1978. X-ray diffraction topographic observations of the large-angle grain boundary in ice under deformation. Fournal of Glaciology, Vol. 21, No. 85, p. 629-38.

Ketcham, W. M., and Hobbs, P. V. 1969. An experimental determination of the surface energies of ice. Philcsophical Magazine, Eighth Ser., Vol. 19, No. 162, p. I $161-73$.

Kobayashi, T., and Furukawa, Y. 1975. On twelve-branched snow crystals. Journal of Crystal Growth, Vol. 28, No. I, p. $21-28$. 
Kobayashi, T., and others. 1976. On twinned structures in snow crystals, [by] T. Kobayashi and Y. Furukawa and K. Kikuchi and H. Vyeda. Journal of Crystal Growth, Vol. 32, No. 2, p. 233-49.

Kronberg, M. L., and Wilson, F. H. 1949. Secondary recrystallization in copper. Transactions of the American Institute of Mining and Metallurgical Engineers, Vol. 185, No. 8, p. $50 \mathrm{O}-14$.

Matsuda, M., and Wakahama, G. 1978. Crystallographic structure of polycrystalline ice. Fournal of Glaciology, Vol. 21, No. 85 , p. $607-20$.

Read, W. T. 1953. Dislocations in crystals. New York, McGraw-Hill Book Co., Inc.

Reuck, A. V. S. de. 1957. The surface free energy of ice. Nature, Vol. 1 79, No. 4570, p. I I I9-20.

Sun, R. C., and Bauer, C. L. I970[a]. Measurement of grain boundary mobilities through magnification of capillary forces. Acta Metallurgica, Vol. i 8, No. 6, p. 635-38.

Sun, R. C., and Bauer, C. L. $1970[\mathrm{~b}]$. Tilt boundary migration in NaCl bicrystals. Acta Metallurgica, Vol. 18, No. 6, p. 639-47.

Suzuki, S. r970. Kōri no bikesshō no sodaika ni kansuru kenkyū. III [Study of grain coarsening of microcrystals of ice. III]. Teion-kagaku: Low Temperature Science, Ser. A, [No.] 28, p. 47-6r .

Suzuki, S., and Kuroiwa, D. 1972. Grain-boundary energy and grain-boundary groove angle in ice. Fournal of Glaciology, Vol. 1 1, No. 62, p. $265^{-77}$.

Washburn, J., and Parker, E. R. 1952. Kinking in zinc single-crystal tension specimens. Transactions of the American Institute of Mining and Metallurgical Engineers, Vol. 194, No. 10, p. 1076-78.

Weertman, J. 1973. Creep of ice. (In Whalley, E., and others, ed. Physics and chemistry of ice: papers presented at the Symposium on the Physics and Chemistry of Ice, held in Ottawa, Canada, I4-18 August 1972. Edited by E. Whalley, S. F. Fones, L. W. Gold. Ottawa, Royal Society of Canada, p. 320-37.)

\section{DISCUSSION}

M. Eldrup: If a grain-boundary contains some molecules which "belong" to the lattices of both grains, how open is the boundary in between, where the lattices mis-match? Will there be open spaces equivalent to say half a vacancy, or one vacancy, or maybe more?

A. Higashi: The mis-matching boundary should not be open, but corresponds more to interpenetrating molecules.

N. K. Sinha: Could you give any comments on the role of grain-boundaries during transient creep, or its role, if any, in initiating fracture in polycrystalline ice?

Higashi: Our experiments so far are limited to the area of small stress and strain, so we have not observed any phenomena associated with transient creep or initiation of fracture.

J. W. Glen: The evidence you have presented for coincidence sites as giving significant reductions of grain-boundary energy and for favouring certain boundary relations would seem to imply that the boundary is thin, that is to say that there is not a layer of disorder several atoms thick. Do you agree, and is your evidence also relevant to boundaries at high temperatures where boundary disorder might be expected to be larger?

Higashi: Yes, in cases of a good-fit CSL boundary, it should be thin, although it is composed of facets and steps between. We have not yet observed the state at high temperature, but it may become more disordered.

C. MAÏ: What are the scanning planes in your topographs, and what interpretation can you give about the contrast of the fine parallel lines one can observe in the grain boundaries? Are they the equal-thickness fringes?

Higashi: The scanning plane is not necessarily one of low indices. The topograph was scanned on the broad surface of the specimens. We believe most of the fine lines on a good-fit CSL boundary are images of steps. Parallel broad lines are the Pendellösung fringes. 